\title{
Lipoma adjacent to scapula in an elderly
}

\author{
Shijima TAGUCHI ${ }^{1}$ \\ Norio TAKAYASHIKI ${ }^{2}$ \\ Hiroaki SATOH ${ }^{3}$
}

\footnotetext{
${ }^{1}$ Department of Dermatology, Mito Medical Center, Tsukuba University, Mito, Japan

${ }^{1}$ Tsukuba Üniversitesi Mito Tıp Merkezi, Dermatoloji Bölümü, Mito, Japonya

2 Department of Pathology, Mito Medical Center, Tsukuba University, Mito, Japan

${ }^{2}$ Tsukuba Üniversitesi Mito Tıp Merkezi, Patoloji Bölümü, Mito, Japonya

${ }^{3}$ Department of Respiratory, Mito Medical Center, Tsukuba University, Mito, Japan

${ }^{3}$ Tsukuba Üniversitesi Mito Tıp Merkezi, Solunum Bölümü, Mito, Japonya
}

An 81-year-old man complained a soft mass in right back, which was noticed a week ago. He had been diagnosed as having chronic obstructive pulmonary disease seven years previously and treated with longacting muscarinic antagonistat our hospital. On physical examination, an egg-sized soft mass was palpable in right back. It seemed to be fixed to the underlying structure or overlying skin. A chest CT scan showed a $5 \times 5 \mathrm{~cm}$ homogenous low density mass, which had the same density as fat, adjacent to right scapula (Figure 1). The lesion was completely removed surgically and it was diagnosed as lipoma pathologically. Retrospectively, not only low attenuation area in both lungs but also the tumor was observed in a chest CT scan taken 6 years previously (Figure 2).

Chest CT scan is sometimes taken repeatedly in patients with known pulmonary diseases, if necessary. Intrathoracic lesions attract attention, but extrathoracic lesions are rarely watched closely in these patients. Lipoma develops any sites in whole body, especially in trunk of middle age or elderly (1). Long-term existence of the lipoma was confirmed in our patient, however, no further action had been taken as the patient had no complaint for several years. Physicians should highlight the attentionto intrathoracic as well as extrathoracic lesion in patients with known pulmonary disease.

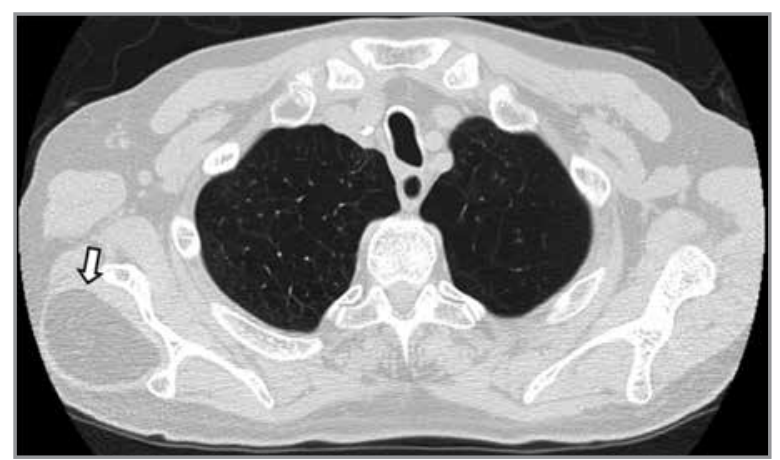

Figure 1. Chest CT scan at the time of detecting a $5 \times 5 \mathrm{~cm}$ homogenous low density mass adjacent to right scapula (arrow).

\section{Yazışma Adresi (Address for Correspondence)}

Dr. Hiroaki SATOH

University of Tsukuba, Division of Respiratory Medicine, Mito Medical Center, TSUKUBA - JAPAN

e-mail: hirosato@md.tsukuba.ac.jp 


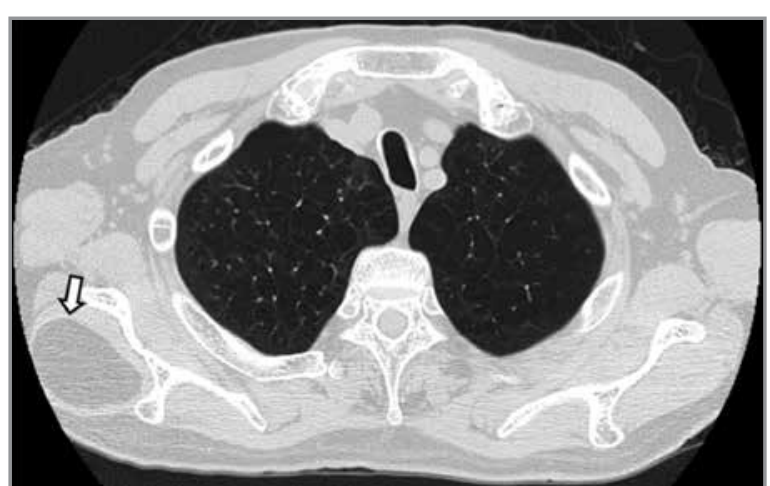

Figure 2. Chest CT scan taken 6 years previously, which already showed low attenuation area as well as the chest wall mass adjacent to right scapula (arrow).

\section{REFERENCE}

1. Dimmock SA, Shaw DG, Pincott JR. Lipoma of chest wall. Case report 326. Skeletal Radiol 1985;14:141-3. 